\title{
Programa Fome Zero e o paradigma da segurança alimentar: ascensão e queda de uma coalizão?
}

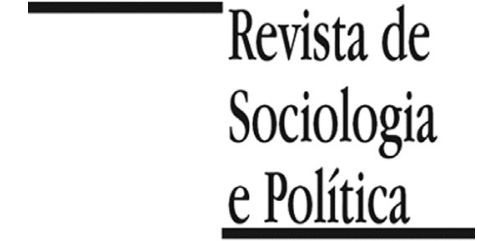

DOI 10.1590/1678-987316245801

\author{
Carla Guerra Tomazini \\ e Cristiane Kerches da Silva Leite
}

\section{Resumo}

O artigo examina o processo de concepção e o progressivo abandono do Programa Fome Zero (PFZ) como principal linha estratégica para as ações do governo federal entre 2003 e 2004. O objetivo é analisar as ideias que estruturam essa política de segurança alimentar e levantar hipóteses sobre sua crise e sobre o redirecionamento para a unificação dos programas de transferência de renda que desembocou na criação do Programa Bolsa Família. A metodologia de pesquisa consiste na análise de dados qualitativos primários (entrevistas semiestruturadas com formuladores do programa) e dados secundários (matérias de jornais, publicações produzidas por pesquisadores especialistas no assunto e trabalhos analíticos sobre o PFZ). O arcabouço teórico utilizado é o de análise de políticas públicas pós-positivista e cognitivista. Após examinar como se deu o processo de formação do paradigma de segurança alimentar no plano internacional e nacional, foram levantadas hipóteses explicativas referentes à crise do PFZ: arranjos institucionais prévios, confronto entre paradigmas, perda de influência da coalizão "segurança alimentar" e a complexidade programática do programa. Argumenta-se que o programa representa um elemento importante para se compreender não somente o jogo político e os problemas gerenciais enfrentados pelo governo recém estabelecido à época, mas a disputa de ideias e de paradigmas travada entre atores e coalizões que buscaram influenciar o combate à fome e à pobreza no primeiro mandato do governo Lula.

PALAVRAS-CHAVE: pobreza; segurança alimentar; transferência de renda; paradigmas; coalizão de defesa.

Recebido em 2 de Outubro de 2014. Aceito em 12 de Janeiro de 2015.

\section{Introdução ${ }^{1}$}

\footnotetext{
1 Os resultados apresentados originaram-se de pesquisa apoiada pela Coordenação de Aperfeiçoamento de Pessoal de Nível Superior (Capes). Agradecemos os comentários à versão anterior, apresentada no Colóquio Réformer le Brésil: un bilan du PT au pouvoir (2003/2014), Université libre de Bruxelles, em junho de 2014. Agradecemos também aos pareceristas anônimos da Revista de Sociologia e Política.

${ }^{2}$ Refere-se à teoria de formação de agenda de autoria do analista de políticas públicas John Kingdon, que será comentada sucintamente mais adiante, na seção teórica.
}

$\mathrm{E}$ m 2003 a posse do presidente eleito Luiz Inácio Lula da Silva representou um ponto de inflexão nas políticas sociais ao colocar a questão do combate à pobreza e à fome no Brasil no centro da agenda governamental. Do ponto de vista kingdoniano ${ }^{2}$, houve uma convergência de fatores que legitimaram essa nova agenda social no país: um contexto internacional propício para a formulação e implementação de programas de combate à pobreza em vários países do mundo, a ascensão ao poder de um grupo político identificado com a ideia da priorização de um programa de segurança alimentar e, especificamente, a posse de um presidente, ou um "empreendedor político" (Kingdon 2003) legitimado por sua trajetória histórica e política referenciada com as classes socialmente excluídas.

O Programa Fome Zero (PFZ) representou inicialmente a principal resposta política na área social do novo governo, formada por iniciativas políticas e institucionais que mobilizaram um conjunto de ministérios, demandando capacidade de articulação intersetorial do governo recém empossado. Do ponto de vista das ideias e dos grupos políticos que as defendiam, representou a ascensão ao processo decisório governamental, em um locus institucional com status de ministério, de um paradigma da ação pública favorável às políticas de segurança alimentar. Conforme veremos mais adiante, essas políticas constituíram um 
${ }^{3}$ Cf. Fome Zero: muito samba, pouco enredo (2001).

${ }^{4}$ Dentre os diversos editoriais e opiniões publicados à respeito dos problemas do programa recém-criado podemos citar: Cheque de Gisele Bündchen... (2003c); Programa Fome Zero tem início... (2003); Brazil's War on Hunger off to a Slow Start (2003).

${ }^{5}$ Para uma resposta às críticas do programa, ver Silva, Belik e Takagi (2002). paradigma, de acordo com o conceito de Hall (1993), ao serem introduzidas pela comunidade epistêmica e política dos think tanks ligados notadamente ao Partido dos Trabalhadores.

Este artigo analisa hipóteses sobre o processo de concepção e de progressivo abandono do programa. A questão parte da seguinte constatação: se o PFZ representava o principal eixo das políticas sociais durante os primeiros anos do primeiro mandato do governo Lula, possuía recursos orçamentários importantes, instituições criadas especialmente para esse projeto e uma imagem positiva junto à opinião pública, quais fatores levaram à sua crise?

Há autores que abordam essa questão enfatizando aspectos de naturezas distintas. A maior parte aponta para a falta de coordenação institucional; a dificuldade de execução devido à complexidade da articulação exigida entre os arranjos ministeriais e federais (Almeida 2004; Hunter \& Power 2005; Hall 2006); o paralelismo com outros programas assistenciais e de combate à pobreza (Monteiro 2003; Yazbek 2004) e a impossibilidade de financiá-1o ${ }^{3}$. Foram apontados erros no diagnóstico do problema (Almeida 2004; Hunter \& Power 2005; Hall 2006); problemas de focalização do programa defendida especialmente por pesquisadores ligados ao IPEA e ao Banco Mundial (Silva, Belik \& Takagi 2002, p.6); promoção da corrupção local (Hunter \& Power 2005); clientelismo político-religioso (Gordillo \& Gómez 2005); falta de conteúdo político e de estratégia de marketing político (Moura 2007). Alguns autores criticaram a concepção conservadora do programa por seu apelo "humanitário, sem claras referências a direitos" (Yazbek 2004). Provenientes tanto dos meios de comunicação como das próprias bases do PT, as críticas também eram direcionadas à "burocracia" do programa ${ }^{4}$. Esperava-se que o programa atingisse rapidamente suas metas e que fosse melhor administrado ${ }^{5}$. De forma incisiva ou en passant, os estudos sugerem a substituição do PFZ pelo Bolsa Família (Almeida 2005; Bourne 2008).

Neste trabalho procuramos dialogar com essa literatura, tendo como premissa que o PFZ, tal como era proposto no início do primeiro mandato do governo Lula, não pode ser tomado somente como um mero acontecimento passageiro "digno de notas de rodapé" ou um primeiro momento do Programa Bolsa Família. A despeito de ter sido extinto com a criação do Programa Bolsa Família, argumenta-se que o PFZ representa um elemento importante para se compreender não somente o jogo político e os problemas gerenciais enfrentados pelo governo recém estabelecido, mas a disputa de ideias e de paradigmas (Campbell 1998; Hall 1993) travada entre os atores que buscavam influenciar a área de combate à fome e à pobreza no primeiro mandato do governo Lula.

Após o desenvolvimento de uma seção metodológica, buscou-se examinar como se deu o processo de formação do paradigma de segurança alimentar no plano internacional e analisar alguns marcos importantes da agenda de segurança alimentar no Brasil. Considerando a possibilidade de os resultados que levaram à formulação e implementação do Fome Zero serem lidos como reflexos de sistemas de crenças dos atores envolvidos, buscou-se identificar a coalizão de atores que defendiam a "segurança alimentar" como principal eixo das políticas de luta contra a pobreza. Em seguida, examinamos algumas hipóteses sobre o processo de concepção e do progressivo abandono do programa, com três subseções: (i) hipóteses explicativas referentes aos arranjos institucionais prévios e às burocracias; (ii) sobre as ideias e a perda de influência da coalizão "segurança alimentar" e (iii) a complexidade programática do Programa Fome Zero. Por fim, apresentamos as considerações finais. 


\section{Orientações teóricas pós-positivistas, cognitivas e normativas}

Nas últimas décadas, um número crescente de estudos tem procurado entender o processo de formulação de políticas públicas sob a perspectiva das ideias (Heclo 1974; Hall 1993; Campbell 1998; Sabatier \& Jenkins-Smith 1993; Jobert \& Muller 1987; Surel 1998; Schmidt 2010). Neste artigo nos baseamos na relação entre ideias e interesses, buscando analisar mais detidamente os grupos que carregam ideias ou paradigmas particulares, que circulam oriundos de think tanks a locus governamentais.

As vertentes tradicionais das análises de políticas públicas reconhecem em geral que as ideias influem em maior ou menor medida na formulação, no processo decisório e na avaliação da ação do Estado. No entanto, os elementos cognitivos são considerados, na maioria dos casos, uma variável explicativa secundária (Faria 2003).

Entre as abordagens que se interessam particularmente pela análise das ideias e dos conhecimentos, cabe observar que a relevância adquirida por esses fatores varia. Em um extremo, encontram-se as teorias de cunho pós-positivista. Essas orientações teóricas fazem um contraponto com as "máximas ortodoxas da economia do bem-estar positivista” (Howllet, Ramesh \& Perl 2013, p.31), criticando a pretensão de objetividade analítica e a neutralidade política. Enfatiza-se a importância da subjetividade, da normatividade interpretativa e argumentação para a compreensão das políticas públicas e do processo de tomada de decisão. Valorizam-se também os fatores sociopolíticos contextuais e idiossincráticos dos casos na análise das políticas públicas (ibid.). Nesse sentido, persuasão, retórica e interpretação figuram como elementos analíticos importantes na orientação pós-positivista.

Embora sejam provenientes de diferentes posicionamentos teóricos, as abordagens que tratamos ao longo do texto utilizam uma perspectiva analítica pós-positivista de forma indireta (Kingdon 2003; Cohen, March \& Olsen 1972; Campbell 2002; 1998; Hall 1993; Sabatier \& Jenkins-Smith 1999). John Kingdon (2003) se aproxima desta orientação ao valorizar o caráter interpretativo do fluxo de problemas e de ideias no seu esquema analítico. Os elementos propulsores de mudança de agenda no esquema kingdoniano dependem de processos normativos, de formação de significados políticos referentes a crises, símbolos e eventos, por exemplo, por parte de atores políticos e sociais. Dessa forma, o conceito de agenda governamental e decisional de Kingdon é constituído de elementos pós-positivistas, mas não necessariamente se esgota nesses. O papel do processo político e da ação do ator político empreendedor é fundamental no esquema explicativo de ocorrência de mudanças políticas. Como a abordagem dos multiple-streams de Kingdon, algumas perspectivas analíticas buscam examinar como se articulam ideias e interesses, com destaque para as noções de paradigmas de Hall (1993), Campbell (2002; 1998) e de advocacy coalitions de Sabatier e Jenkins-Smith (1999). Apesar das diferenças significativas, um ponto comum dessas análises é o questionamento amplo da influência de padrões sociais globais no comportamento social e nas políticas públicas (Surel 1998, p.162). De acordo com Surel (idem), os conceitos de paradigma de Peter Hall e o sistema de crenças proposto por Paul Sabatier partem de uma mesma constatação: preceitos abstratos definem o âmbito das possibilidades numa determinada sociedade, instituindo "matrizes cognitivas e normativas"6. Essas se caracterizam como sistemas coerentes de elementos normativos e cognitivos que definem "visões de mundo" e "cartas mentais" dentro de um determinado campo. De maneira global, uma matriz paradigmática de política pública integra mecanismos identitários, princípios de ação, bem como prescrições metodológicas e práticas de atores (idem, p.162). 
${ }^{7}$ As traduções de língua estrangeira são responsabilidade das autoras, salvo menção especial.

${ }^{8}$ Cabe destacar que a despeito do ganho analítico, crenças e valores causais são virtualmente inseparáveis.
Hall (1993) explora a mediação entre as ideias e os resultados políticos específicos por meio do conceito de aprendizagem social. Esse autor está interessado em discutir como as ideias e os interesses interagem em contextos institucionais específicos para produzir mudanças políticas. Convencionalmente, "aprendizagem ocorre quando indivíduos assimilam novas informações, incluindo a baseada em experiências passadas, e aplicam suas ações subsequentes" (idem, p.278). Assim, nós podemos definir aprendizagem social como uma tentativa deliberada de ajustar as metas ou técnicas de política em resposta a experiências passadas (ou a conhecimento relevante para a política) e novas informações. "Há aprendizagem quando mudanças políticas são resultado de tal processo" (ibid.). Especificamente com relação ao processo de aprendizado social, Hall (idem) argumenta que este processo pode ser desagregado em três variáveis centrais e três ordens de mudança: as grandes metas que guiam as políticas em um campo particular - os grandes paradigmas de ideias que balizam as políticas e programas; as técnicas ou instrumentos de política - ou desenho - para atingir as metas; e os conjuntos mais específicos desses instrumentos operacionais (idem, p.278).

A fim de compreender como as ideias podem influenciar no processo de decisão política, Campbell $(1998 ; 2002)$ distingue duas categorias de ideias: cognitivas e normativas ${ }^{8}$. A primeira categoria diz respeito ao campo do conhecimento e das análises teóricas, estabelecendo relações entre causas e efeitos. A segunda categoria refere-se às ideias subjacentes e premissas assumidas nos valores e atitudes. Além dessa tipologia, Campbell distingue as ideias que fazem parte do debate em um primeiro plano de políticas públicas e outras mais contextuais que estariam em um segundo plano. Assim, as ideias paradigmáticas dizem respeito ao campo normativo e aos elementos contextuais de políticas públicas. Elas definem o terreno do discurso das políticas públicas e dizem respeito às premissas teóricas e ontológicas sobre o funcionamento do mundo. Nesse sentido, ganham evidência universidades, think tanks e organizações profissionais que fornecem as bases para determinadas visões de mundo aos tomadores de decisões. Dentro dessa categorização, cabe constatar que as ideias programáticas e as ideias paradigmáticas assemelham-se aos conceitos de Sabatier e Hank Jenkins-Smith (1999) sobre as crenças duras e as crenças relativas a uma determinada política pública.

O modelo de Sabatier e Hank Jenkins-Smith sobre advocacy coalitions busca compreender as interações no interior das distintas coalizões de atores. Esses são provenientes de diferentes instituições governamentais e não governamentais e se reúnem em coalizões de causa (ou coalizões de defesa) por compartilharem um conjunto de policy beliefs e por atuarem dentro de uma dada área setorial (subsistema de política pública). Nesse modelo, as mudanças nas políticas podem ser produto de eventos externos, como fruto da competição, interação e aprendizagem das coalizões. Como indica o Quadro 1, as coalizões se formam em torno de um sistema de crença dividido em três níveis. O nível mais profundo é composto de axiomas normativos duros, cujas mudanças são menos prováveis. Esses núcleos duros de representações e crenças se refletem no segundo nível, no núcleo de políticas (policy core), isto é, nas posições acerca das direções da ação pública. Finalmente, a camada mais propícia à mudança é aquela que diz respeito aos aspectos secundários e às decisões instrumentais das políticas. No modelo de advocacy coalitions também ganha destaque o papel do conhecimento e da produção científica. No entanto, diferentemente do conceito de comunidades epistêmicas (Haas 1992), a ênfase se coloca nos valores e não na produção de conhecimento. Além de ser um conceito mais abrangente, de acordo com Radaelli (2013, p.26), o modelo ACF "oferece uma ligação entre políticas públicas [policy] e política [politics]"”. Os modelos são resumidos no Quadro 1. 
Quadro 1 - Ideias que produzem efeitos nas políticas públicas (segundo Campbell e Sabatier)

\begin{tabular}{|c|c|c|c|}
\hline \multirow[b]{3}{*}{$\begin{array}{l}\text { Segundo plano de políticas } \\
\text { públicas }\end{array}$} & Nível Cognitivo & \multicolumn{2}{|c|}{ Nível Normativo } \\
\hline & Advocacy coalitions & \multicolumn{2}{|c|}{ Modelo de Campbell (1998) } \\
\hline & $\begin{array}{l}\text { Núcleo de valores } \\
\text { Fundamentais }\end{array}$ & $\begin{array}{l}\text { Paradigmas: Assunções de } \\
\text { fundo que limitam o escopo } \\
\text { das alternativas consideradas } \\
\text { úteis e viáveis }\end{array}$ & $\begin{array}{l}\text { Sentimentos públicos: } \\
\text { Premissas e percepções das } \\
\text { elites sobre o que o público } \\
\text { vai aceitar como legítimo ou } \\
\text { não }\end{array}$ \\
\hline $\begin{array}{l}\text { Primeiro plano de políticas } \\
\text { públicas }\end{array}$ & $\begin{array}{l}\text { Policy core: Crenças próprias } \\
\text { ao subsistema específico da } \\
\text { política pública } \\
\text { Aspectos secundários } \\
\text { relativos aos detalhes } \\
\text { específicos }\end{array}$ & $\begin{array}{l}\text { Programas: Prescrições de } \\
\text { políticas públicas que } \\
\text { especificam como resolver } \\
\text { determinados problemas }\end{array}$ & $\begin{array}{l}\text { Frames: Reivindicações } \\
\text { normativas que as elites } \\
\text { utilizam para legitimar } \\
\text { alternativas políticas para o } \\
\text { público }\end{array}$ \\
\hline
\end{tabular}

Fonte: As autoras, a partir de Campbell (1998) e Sabatier e Jenkins-Smith (1999).

Parece possível sugerir que, para esses autores, a análise da mudança de políticas públicas não pode prescindir das ideias e do exame atento de suas diferentes dimensões. As três perspectivas (i.e, Hall, Sabatier e Campbell) possuem similaridades entre si ao tratar da forma como as elites operam no interior dos diferentes subsistemas de políticas públicas. Elas partilham a premissa de que atores não estão somente preocupados com os próprios interesses, uma vez que as crenças e as percepções parciais do problema público desempenham um papel crucial na evolução e na mudança das políticas. O surgimento de uma nova matriz não se produz com a substituição de um paradigma por outro, mas sim por meio de novas associações e novos arranjos oriundos de outros paradigmas pré-existentes mais ou menos antigos (Surel 1998, p.172).

Para nossa análise, foram mobilizados esses conceitos e modelos teóricos a fim de compreender a evolução do PFZ à luz de fatores que são frequentemente negligenciados: produção do conhecimento científico e da expertise, assim como as crenças e representações dominantes compartilhadas por diferentes atores que circulam entre as esferas públicas e privadas. O principal objetivo é analisar o processo de concepção e progressivo abandono do PFZ como linha estratégica para as ações do governo federal. Partimos da constatação de que a temática da segurança alimentar, embora tenha se institucionalizado no governo federal notadamente com a criação do CONSEA em 2003, permanece como uma estratégia marginal da intervenção governamental em matéria de políticas sociais de luta contra a pobreza, voltada fortemente para as transferências de renda, com a criação do Programa Bolsa Família.

Buscou-se, enfim, entender, à luz das teorias pós-positivistas, cognitivas e normativas, como a temática da segurança alimentar se consolidou como um paradigma de política pública ao longo dos anos 1990 para introduzir-se de modo significativo na agenda do novo governo federal em 2003. Compreender as razões por trás dessa tentativa é relevante na medida em que, conforme Faria (2003), as análises de políticas públicas no Brasil que se dedicam a compreender o impacto das ideias e do conhecimento não foram completamente incorporadas à produção acadêmica brasileira.

\section{Metodologia e estratégias de pesquisa}

Trata-se de uma análise qualitativa de dados primários e secundários. Os dados qualitativos primários consistem, sobretudo, em entrevistas semiestru- 
${ }^{10}$ Matérias jornalísticas foram fontes secundárias de dados. ${ }^{11}$ Pesquisa de doutorado de Carla Tomazini realizada em cotutela na Unicamp e na Universidade Paris III, Institut des Hautes Études de l'Amérique Latine, que se intitula: «L'État et ses pauvres: la naissance et la montée en puissance des politiques de transferts conditionnels au Brésil et au Mexique».

${ }^{12}$ Ver lista de entrevistados no anexo. A seleção dos entrevistados foi baseada na percepção de que se tratam de atores estratégicos fundamentais no processo decisório e nas mudanças observadas. turadas ${ }^{10}$. Foram realizadas entrevistas no âmbito da pesquisa de doutorado de uma das autoras ${ }^{11}$, com atores-chave envolvidos com o Programa Fome Zero. Estes integram o subsistema analisado, a partir de diversos locus institucionais, como membros do Fórum Brasileiro de Segurança Alimentar, presidentes do CONSEA, especialistas em segurança alimentar (que fazem parte de redes internacionais) e os coordenadores técnicos do $\mathrm{PFZ}^{12}$. As ideias paradigmáticas, crenças e valores permitem estruturar o quadro de hipóteses que se objetiva desenvolver neste trabalho. As entrevistas versaram, em linhas gerais, sobre a trajetória histórica do paradigma de segurança alimentar e as trajetórias dos próprios atores no processo de formulação e implementação do programa, assim como de atores inseridos em instituições que se formaram como think tanks em anos anteriores à criação do PFZ. Desta forma, foram realizadas entrevistas semiestruturadas, mas com características de entrevista em profundidade. Conforme Martins e Theóphilo (2009, p.89):

"Denomina-se em profundidade uma entrevista não estruturada em que o respondente é abordado por um entrevistador, altamente treinado, para obtenção de informações detalhadas sobre tema específico, a fim de levantar motivações, crenças, percepções e atitudes em relação a certa situação e/ou objeto de investigação".

Os dados secundários referem-se a publicações produzidas por pesquisadores especialistas no assunto, trabalhos analíticos sobre o Fome Zero e o conceito de segurança alimentar. Na perspectiva de mapear os atores políticos estratégicos e analisar suas ideias e crenças, foram explorados também, além das entrevistas, trabalhos acadêmicos de autoria de técnicos especialistas que participaram ativamente do "ciclo de vida" do PFZ.

\section{Formação do paradigma de segurança alimentar no plano internacional e no Brasil: destacando alguns aspectos}

Enquanto paradigma de políticas públicas, a temática da segurança alimentar ganhou contornos internacionais e saliência na agenda dos governos a partir da II Guerra Mundial. Na construção da imagem (policy image) (Baumgartner \& Jones 2009) da política de segurança alimentar foi fundamental o processo de criação da FAO no âmbito da ONU, em 1945. Uma das ideias motrizes, de caráter liberal, era a "libertação da necessidade", que se daria pela superação da fome e a realização das necessidades básicas para uma vida digna (Takagi 2006). Outra ideia-força associada à segurança alimentar, naquele contexto, era a de segurança nacional:

“A noção do alimento como poderosa arma política entre os países surgiu pela primeira vez naquele pós-guerra, frente aos riscos ocasionados pela destruição em massa de campos de produção de alimentos. A alimentação adquiriu um significado estratégico de segurança nacional, impondo a necessidade a cada país de assegurar por conta própria o suprimento da maior parte dos alimentos que sua população consome, inaugurando um conjunto de políticas específicas, entre as quais a formação de estoques de alimentos" (Maluf \& Menezes apud Takagi 2006, p.12).

Entre as décadas de 1940 e 1990 houve uma série de mudanças e processos políticos que marcaram a trajetória histórica do paradigma de segurança alimentar. Esses fatos não são o objeto deste trabalho, mas devem ser citados na medida em que se argumenta que o conteúdo do paradigma atual é fruto de um processo histórico. Na década de 1970 a crise alimentar associada à crise econômica mundial reforçou a politização da noção de alimento, em um contexto propício para política de combate à fome. Na mesma época, as reações à crise se deram com a I Conferência Mundial de Alimentação, de iniciativa da 
13 "Os "intitulamentos" de Sen podem assumir a forma de acesso a bens ou recursos, por meio de canais legais de aquisição: recursos para coletar ou produzir alimentos; recursos que permitem a troca (propriedades, dinheiro, força de trabalho) por alimentos; e o recebimento de doações de alimentos ou de recursos para acessá-los. Este conceito amplia, portanto, as formas de acesso à alimentação por parte dos indivíduos, além do simples aumento da oferta dos mesmos" (Takagi 2006, p.14).
FAO, e a Revolução Verde, que forneceu "suporte ideológico e político necessário para a adoção e disseminação do modelo agrícola de emprego maciço de insumos químicos (fertilizantes e agrotóxicos), sementes melhoradas e máquinas agrícolas" (Takagi 2006, p.13). Até os anos 1980, a ideia predominante se vinculava à oferta de alimentos, ou seja, uma noção de política de assistência alimentar. A ênfase na demanda se deu com Amartya Sen, em 1981, com seu conceito de entitlement ${ }^{13}$.

Nos anos 1980 sedimentou-se um conceito de segurança alimentar que permanece até a atualidade: à noção de oferta suficiente de alimentos incorporou-se a noção de acesso aos alimentos, de qualidade e de regularidade da alimentação. No Brasil, segundo Takagi (2006), a temática de segurança alimentar foi introduzido em 1985, por meio de um documento para uma política de abastecimento no Ministério da Agricultura, tendo como panorama o início da disseminação do tema na América Latina, capitaneado pela FAO e pela Cepal (idem, p.17-18). Os gestores trabalharam com uma noção ampla da questão alimentar, mais próxima daquela adotada pela FAO, que colocava ênfase na autossuficiência alimentar nacional, mas já apontava como causa da falta de acesso aos alimentos a insuficiência de renda (idem, p.18). Na mesma época, houve uma série de eventos e criações institucionais que marcavam o conteúdo paradigmático que foi politicamente institucionalizado no Brasil: criação do Conselho Nacional de Segurança Alimentar, como um fórum de decisões, presidido diretamente pelo Presidente da República e cujo secretárioexecutivo seria o Ministro da Agricultura; ocorrência da I Conferência Nacional de Alimentação e Nutrição, na qual se afirmou a compreensão de que a alimentação é um direito básico. Desse modo "a identificação da incapacidade do acesso aos alimentos por parte significativa da população brasileira frente à pobreza e ao desemprego, como uma de suas causas principais, ganhava destaque no diagnóstico da situação de insegurança alimentar do país" (ibid.).

A partir da Conferência Mundial sobre Direitos Humanos em 1993, as discussões sobre o status de direito humano gera uma mudança fundamental no paradigma de segurança alimentar, tendo impactos significativos no Brasil. Além de uma mudança de status jurídico, surge um processo de responsabilização política: "a mudança fundamental na forma de encarar o direito à alimentação e o compromisso internacional de redução das estatísticas relacionadas com a fome colocam o Estado na posição de provedor e responsável pelo bem-estar alimentar de sua população" (Belik 2003, p.13). "Baseado no princípio do direito à alimentação, os governos poderiam receber censuras em nível internacional, por não garantir o acesso dos seus cidadãos à alimentação" (idem, p. 14), pelos órgãos da ONU.

No Brasil, no início dos anos 2000, um relatório da Comissão de Direitos Humanos da ONU sobre direito à alimentação expôs mundialmente o péssimo quadro da fome e da desnutrição de milhares de brasileiros na época. $\mathrm{Na}$ perspectiva kingdoniana de mudança de agenda, em 2003, esse movimento internacional gerou pressão sobre o processo decisório no contexto da eleição do presidente Lula, alavancando a abertura de uma janela de oportunidade para a criação de novas políticas de combate à fome. O movimento de atores internacionais conjugou-se com a mobilização de atores coletivos nacionais atrelados a movimentos sociais e representação empresarial.

O combate à fome se configura como um elemento mobilizador da sociedade brasileira desde os anos 1990. O processo de sensibilização, ou a criação de um sentimento público positivo (Campbell 1998), dos atores políticos e sociais com relação ao tema da fome e combate à pobreza deita em raízes históricas, tendo como marco, nos anos 1990, a criação da ONG Ação para Cidadania contra a Fome, a Miséria e pela Vida, liderada pelo sociólogo Herbert 
de Souza (Betinho). Takagi (2006) destaca também iniciativas que geraram um acúmulo de experiências e propiciaram a disseminação de ideias e aprendizagem social entre atores políticos e sociais. Um exemplo da difusão das ideias de segurança alimentar entre as prefeituras administradas pelo PT é o seminário "Fome - Desafio dos Anos 90", organizado pela prefeitura de São Paulo, na gestão da ex-prefeita Luiza Erundina, no qual se discutiu ações de abastecimento alimentar no âmbito municipal. O governo paralelo liderado pelo Lula durante o governo Collor de Mello representou uma etapa importante na trajetória do tema da segurança alimentar dentro do PT e entre os think tanks ligados ao partido, conforme será abordado na próxima seção.

Em síntese, segundo Takagi (2006), essas ações somadas ao trabalho de Herbert de Souza promoveram, no governo Itamar Franco, a criação do CONSEA, que tinha como objetivo coordenar a elaboração e a implantação do Plano Nacional de Combate à Fome e à Miséria, dentro dos princípios da solidariedade, parceria e descentralização (idem, p.20). A criação do CONSEA contribuiu para incluir, de forma efetiva, a segurança alimentar na agenda política brasileira, por meio da criação institucional, imprimindo um caráter de parceria sociedade-governo devido à formação de uma representação civil direta que buscava conferir legitimidade ao tema no governo (IPEA apud Takagi 2006). Com a criação do CONSEA o combate à fome e à miséria passou a ser visto como um problema de governo e uma questão estratégica, ficando sua coordenação diretamente vinculada ao gabinete do Presidente da República. Diante disto, implantaram-se mecanismos de intersetorialidade governamental, nos diferentes níveis de governo, incluindo ações da sociedade civil no sentido de reduzir duplicidades, superposições e de atingir os objetivos propostos. $\mathrm{Na}$ gestão de Fernando Henrique Cardoso o CONSEA foi extinto logo no início do mandato, substituído por outro conselho, o Comunidade Solidária, de caráter consultivo e com ênfase na coordenação de ações de combate à pobreza e à miséria e mantendo a parceria entre sociedade civil e Estado. A segurança alimentar foi deslocada para segundo o plano como eixo estratégico de governo, embora se mantivessem iniciativas governamentais isoladas (idem, p.21).

Como vimos, há algumas décadas, a construção do paradigma de segurança alimentar e nutricional vem se colocando como uma alternativa na elaboração de políticas públicas no Brasil. Apesar de ter apresentado variações ao longo do tempo, esse paradigma estabelece uma relação de causa e efeito (insegurança alimentar e nutricional como causa da pobreza) de forma a produzir respostas específicas de políticas públicas. Nesse sentido, o modelo de advocacy coalition pode contribuir para a análise do PFZ ao examinar de que forma as ideias atreladas à temática da segurança alimentar e nutricional exercem uma função aglutinadora na conformação da coalizão de atores que as defendem.

Uma das crenças fundamentais dos atores membros da coalizão segurança alimentar diz respeito ao direito a uma alimentação regular, digna em quantidade adequada e nutricionalmente equilibrada (Tomazini 2010). Para os atores dessa coalizão, ainda que a maioria da população em extrema pobreza pode não passar fome, ela dependeria na maior parte dos casos de favores e de ações filantrópicas, se alimentando muitas vezes de forma indigna. No entanto essa coalizão não estava sozinha. Entre as décadas dos anos 1990 e 2000, as políticas de luta contra a pobreza podem ser analisadas como o produto de interação entre coalizões: uma coalizão que defendia os princípios da segurança alimentar, outra que defendia as premissas do capital humano e uma terceira favorável à renda básica universal (idem). Apesar de não ser objeto deste trabalho, essas coalizões foram importantes para a queda do PFZ, como veremos adiante. 


\section{Coalizão de causa "segurança alimentar" e o Partido dos Trabalhadores (PT) (1989-2002)}

Um marco importante na formação da coalizão "segurança alimentar" foi o "Governo Paralelo", que surgiu a partir da derrota do candidato Lula nas eleições presidenciais de 1989. Em 1991, por iniciativa do grupo que atuou na campanha derrotada para a presidência, foi lançado um documento intitulado "Política Nacional de Segurança Alimentar". De autoria de Luiz Inácio Lula da Silva e José Gomes da Silva (pai do José Graziano da Silva, futuro coordenador do Projeto Fome Zero), o tema da segurança alimentar surgiu com a preocupação de levantar políticas para o acesso aos alimentos, completando a outra face da moeda que era a das políticas agrícolas e agrárias, voltadas para a oferta. O relator da proposta foi o professor Renato Maluf, na época gestor municipal, que também atuou na proposta do Ministério da Agricultura, de 1985. Ideias básicas desse documento foram resgatadas como, por exemplo, a criação da Secretaria Especial para a Segurança Alimentar, vinculada à Presidência da República, e do Conselho Nacional de Segurança Alimentar, com o intuito de integrar setores governamentais de diferentes unidades federais, estaduais e municipais assim como de representantes dos segmentos sociais (Takagi 2006, p.19). Em uma entrevista concedida à Renato Simões, José Gomes da Silva descreve:

"Nesse período eu fui a um congresso de Direito Agrário na Itália, visitei a FAO, conversei com as pessoas e fiquei impressionado com as propostas de segurança alimentar, que já era um conceito universal, menos no Brasil, onde havia uns tabus em relação à questão da fome, da desnutrição, da carência. E achei que esse conceito de segurança alimentar tinha, politicamente, um sabor muito forte para se contrapor à segurança nacional, que era a bandeira militar no período da ditadura. Com a grande vantagem de ter o aval, o respaldo, das Nações Unidas e de não ter sido o Governo Paralelo ou a esquerda quem inventou o conceito. [...] Até que o Lula resolveu transformar isso numa bandeira política [...]. O fato de colocar o Betinho e D. Mauro Morelli à frente dele, deu uma outra força, incluiu uma outra área e um outro contingente. $\mathrm{O}$ Betinho também tem sido muito feliz em sensibilizar o governo com sua figura mística" (Gomes da Silva 1993; sem grifos no original).

Para além de uma proposta partidária, o projeto de segurança alimentar se transformou em uma proposta de governo, sendo abraçada pelo presidente à época Itamar Franco. Conforme relato de Renato Maluf (2009), a questão da fome é um elemento que possibilita a articulação de diferentes setores, pois "a decisão de se formular uma política de segurança alimentar é resultado da sensibilidade da temática e da proximidade com movimentos sociais". Do Governo Paralelo surgiu o Instituto Cidadania, ONG criada em meados dos anos 1990 com o intuito de fomentar um debate de caráter mais executivo e voltado para projetos de políticas públicas, aglutinando especialistas ligados ao PT, mas sem vínculo com a estrutura partidária, sob a liderança política, novamente, de Luiz Inácio Lula da Silva.

Conforme relato de Maya Takagi (2009) e de Renato Maluf (2013), o documento de 1991 do governo paralelo foi fruto de um processo de legitimação marcado por longos debates envolvendo centenas de especialistas em Fóruns de Segurança Alimentar, entidades da sociedade civil, parlamentares, religiosos, sindicatos, empresários e especialistas nacionais e internacionais que analisaram e propuseram modificações ao documento base. De forma similar, ao longo do ano de 2001, com o intuito de discutir o projeto em nível nacional, a equipe de especialistas contratada pelo Instituto Cidadania promoveu três seminários em São Paulo, Fortaleza e Santo André. Esses seminários contaram com a participação de lideranças políticas, representantes de centrais sindicais e movimentos sociais (como Central Única dos Trabalhadores, da Confederação 
Nacional dos Trabalhadores na Agricultura, Federação dos Trabalhadores na Agricultura Familiar, Central de Movimentos Populares, Movimento dos Trabalhadores Rurais Sem Terra etc.), pesquisadores e especialistas em segurança alimentar, empresários, representantes de ONG (como a Ação da Cidadania, Instituto Ethos e Articulação Semiárido Brasileiro etc.), representantes religiosos e representantes de algumas prefeituras municipais, entre outros (Fome Zero 2001). No Dia Mundial da Alimentação, em 12 de outubro de 2001, o projeto Fome Zero foi lançado no Senado Federal, permanecendo na agenda política do país desde então (Takagi 2006, p.24-25).

Ainda que a temática da segurança alimentar tenha se tornado uma bandeira do governo Lula em 2003, alguns dos entrevistados insistem no fato da proposta estar mais atrelada à figura do Lula e ao Instituto de Cidadania e menos à orientação programática partidária do PT. Destaque para a atuação dos economistas da comunidade epistêmica da Universidade Estadual de Campinas (Unicamp): José Graziano, Walter Belik, Maya Takagi, entre outros. Vale frisar que passou pela mesma universidade, mas por meio de outro locus institucional (o Núcleo de Pesquisas em Políticas Públicas - NEPP), o grupo ligado à Ana Fonseca, que iria capitanear o processo de unificação dos cartões e implementação do Bolsa Família no contexto de crise do PFZ (Leite \& Peres 2015).

O Instituto Cidadania teve um papel importante na formulação do PFZ. De acordo com Takagi (2013), a seca que atingiu a região Nordeste em 1998 e as Caravanas da cidadania de 1999 foram fatores imediatos que incitaram a retomada da proposta de política de segurança alimentar, uma vez que se compreendeu a necessidade de formular uma agenda voltada para essa temática.

A trajetória da segurança alimentar, do ponto de vista da análise das políticas públicas, é marcada por um claro processo de acúmulo de experiências e aprendizado social (Hall 1993), como demonstra a retomada de ideias anteriormente debatidas e legitimadas, mas que não tiveram força política para imprimirem-se na agenda do governo federal. Cabe notar o papel dos estados e municípios nas iniciativas de políticas ligadas a essa temática. Conforme relatou Takagi (2013) em entrevista: "do meu ponto de vista, a segurança alimentar como política pública local surgiu nas prefeituras municipais do PT como em Piracicaba, Santo André, Diadema, Belo Horizonte etc”. Renato Maluf (2013) especifica que o CONSEA se inicia nos estados e não no nível federal. Dessa forma, a marca bottom-up de formação da proposta dentro do PT e o papel catalisador do Lula como empreendedor político salientaram-se em vários capítulos desse processo.

\section{O Programa Fome Zero (2002-2003)}

Poucos dias depois da posse do Presidente Lula em 2003, o PFZ foi lançado em meio a um grande alvoroço de agências e fóruns internacionais, dos governos estrangeiros e da sociedade civil. Em um primeiro momento, celebridades doaram cachês ${ }^{14}$, empresas se apressaram a fazer doações, mutirões de arrecadação de alimentos se constituíram e um núcleo de atendimento especial foi criado para atender doadores de empresas, entidades de classe, ONG e pessoas físicas interessadas em estabelecer parceria com o programa (Takagi 2006). No nível internacional, instituições financeiras como o Fundo Monetário Internacional, Banco Mundial e Banco Interamericano também se prontificaram a endossar as ações antipobreza do governo Lula (Hall 2006). Institucionalmente, o PFZ contava com estruturas específicas como o Ministério Extraordinário de Segurança Alimentar e Combate à Fome (MESA), o Conselho Nacional de Segurança Alimentar e Nutricional (CONSEA) e com a presença de representantes da sociedade civil e do governo. As iniciativas do programa abrangiam um largo espectro de ações que envolviam desde formas de organização

${ }^{14} C f$. Cheque de Gisele Bündchen para o Fome Zero... (2003).

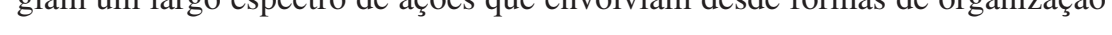


${ }^{15} \mathrm{O}$ conceito de segurança alimentar presume que quatro condições de acesso aos alimentos sejam cumpridas: quantidade adequada, equilíbrio nutricional, regularidade da oferta e dignidade para obtê-lo". (Instituto Cidadania 2001, p. 15).

${ }^{16}$ Dentre as empresas doadoras do PFZ encontraram-se grandes associações empresariais, comerciais e industriais, bancos e instituições financeiras, empresas pertencentes ou não ao setor alimentício como Laboratórios Pfizer, Bayer, Coca-Cola, Nestlé Brasil, Pão de Açúcar, Carrefour, Editora Globo, Shell Brasil, Unilever e Volkswagen (Campos \& Abreu 2010).

${ }^{17}$ Os comitês gestores eram responsáveis pela seleção das famílias beneficiárias e contavam majoritariamente com atores da sociedade civil. por bairro a assentamentos agrários e restaurantes populares, bancos de alimentos, transferências condicionadas à frequência escolar. Tamanha proporção demandava o envolvimento de vários ministérios e das três esferas do governo.

O objetivo principal do PFZ era garantir o direito humano à alimentação por meio da promoção da Segurança Alimentar ${ }^{15}$, compondo ações e programas articulados pelo Governo Federal com estados, municípios e sociedade civil. Há indícios de que grupos empresariais influentes apoiaram as propostas do PFZ, propondo-se até mesmo a contribuir. Grandes empresas públicas e conglomerados, associações empresariais privadas e cadeias de supermercados foram convidadas a participar, sugerindo uma nova forma de relacionamento entre setor público e setor privado, configurando uma responsabilidade social diferente (Hall 2005) ${ }^{16}$. Além disso, nomeou-se um coordenador específico da área de mobilização empresarial da Assessoria Especial de Mobilização Social da Presidência da República, Oded Grajew, visando incentivar as empresas públicas e privadas a colaborar com as ações do PFZ.

A despeito do PFZ obter, em um primeiro momento, apoio político de grupos empresariais, da sociedade civil organizada e da Presidência da República, o programa enfrentou desde o início da sua implementação algumas dificuldades.

Dentre os conflitos conceituais na implementação do PFZ, podemos destacar quatro. Primeiramente, segundo nossas entrevistas, o debate ocorreu já na equipe de transição com relação à proposta de criação de um programa alimentar baseado no programa americano Food Stamp. As controvérsias no seio da própria equipe levaram à opção por um programa de transferência direta em dinheiro ao invés dos "cupons ou cartões eletrônicos que seriam utilizados para as compras de alimentos em varejistas previamente cadastrados" (Fome Zero 2001, p.35). Essa primeira mudança no desenho de um dispositivo do PFZ foi fruto de muitos debates e do convencimento por parte da equipe do Fome Zero de que o modelo de transferência de renda dos programas como Bolsa Escola apresentavam custos menores e já eram “consagrados” (Takagi 2013). Ainda sobre o Cartão Alimentação, Maya Takagi (2013) e José Francisco Graziano da Silva (2009) destacam que a controvérsia se estendeu também ao comprovante de compras dos alimentos. Outro ponto importante apontado por nossos entrevistados (Crispim Moreira 2009; Carlos Alberto Libânio Christo (Frei Betto) 2009; Maya Takagi 2013) diz respeito à criação dos comitês gestores ${ }^{17}$. O conflito se deveu às diferenças de concepção sobre o papel da sociedade na execução do programa e da capacidade das prefeituras em identificar e cadastrar as famílias (Tomazini 2015). Finalmente, no que se refere à questão do diagnóstico do número de pessoas vivendo abaixo da linha da pobreza, os dados sobre a extensão da pobreza apresentados pelo PFZ receberam críticas de diversos tipos.

O PFZ estabeleceu o diagnóstico de 44 milhões vivendo em insegurança alimentar em 1999 ou 27,8\% da população brasileira. Esse diagnóstico era substancialmente maior que aquele apresentado pelo Instituto de Política Econômica Aplicada (Barros, Henriques \& Mendonça 2001): a população com renda abaixo da linha de indigência representaria somente 22 milhões de pessoas ou $14 \%$ da população em 1999. Para os atores reunidos em torno da causa "segurança alimentar", essa diferença se explica pela maior abrangência da noção de segurança alimentar, uma vez que ela leva em consideração os indivíduos que vivem em uma incerteza sobre como se alimentarão no futuro (Tomazini 2010a; 2010b). Takagi (2006) ressalta que algumas críticas baseadas nos estudos encomendados pelo próprio governo ao IPEA, questionavam não somente a metodologia utilizada pelo PFZ, mas a ideia de colocar a fome na agenda de prioridades do governo. Desse modo, o conflito entre os diferentes 
sistemas de crenças e valores pode ser observado desde os momentos iniciais do programa tanto no que diz respeito ao desenho e ao diagnóstico do problema quanto às prioridades da ação do estado.

\section{Hipóteses explicativas sobre a crise do Programa Fome Zero}

Nesta subseção abordaremos as hipóteses sobre as mudanças de políticas que permitiram o abandono paulatino do PFZ. Uma primeira hipótese diz respeito à "dependência de trajetória" (Pierson 2000; 2004), ancorada na ideia de que eventos históricos e/ou escolhas passadas delimitam o campo de ação dos atores, cerceando o rol de possibilidades a serem consideradas no futuro. Por exemplo, em entrevista, Patrus Ananias (2009) faz a seguinte observação sobre as mudanças que levaram à incorporação do Cartão Alimentação ao Bolsa-Família:

"Na ocasião, havia programas de transferência de renda, dispersos e fragmentados. O Bolsa Família assumiu um outro desenho, mais amplo, com foco definido na família, no núcleo familiar. É um programa que superava a fragmentação dos outros e que se apresenta como propósito de atender todas as famílias pobres e muito pobres. Não era possível interromper o pagamento dos benefícios dos outros programas para começar a implementar outro. Costumo usar uma imagem para nosso desafio: tínhamos de trocar o pneu com o carro em movimento".

As transferências de renda condicionadas existentes teriam um feedback positivo de política, servindo como uma "ponte natural" para o desenho de um programa de transferência condicionada de grande porte.

Além disso, os arranjos administrativos previamente desenvolvidos nos estados e municípios, particularmente, localizados no Sul e no Sudeste do Brasil, teriam contribuído para a criação de uma concorrência entre os objetivos das políticas de bem-estar, que pode explicar em parte a crise do PFZ. Além disso, cabe lembrar que o PT possuía a maior parte de suas prefeituras localizadas nessas regiões, trazendo essas lideranças para o governo federal em 2003 (Takagi 2006). Desse modo, as diferenças de concepções quanto às prioridades de políticas sociais também estão colocadas em termos regionais. O PFZ estava mais voltado para uma visão de política direcionada aos problemas da região Nordeste do Brasil. No entanto, essa argumentação também não explicaria de forma satisfatória o desenrolar do PFZ porque poderiam ter convivido lado a lado programas com objetivos diferentes.

Uma hipótese importante sobre a crise do programa relaciona-se com a literatura que aponta para a autonomia do Estado (Skocpol 1979; 1985). Os funcionários públicos e políticos seriam atores de peso com poder de agenda, cujas metas e ações não são reduzidas às exigências e preferências de grupos de interesse, movimentos sociais ou luta de classes. As burocracias do Estado seriam capazes de promover a expansão das políticas sociais, caso possuam capacidade administrativa, recursos fiscais, infraestrutura organizacional (Orloff \& Skocpol 1984; Skocpol 1985; Weir \& Skocpol 1985). De um lado, a capacidade do Estado, tanto institucional como orçamentária, não explica de modo satisfatório a crise do PFZ, porque não colocaria à prova as iniciativas ligadas ao programa. Diretamente vinculado à Presidência da República, o

MESA contava com acesso privilegiado e assistência do próprio presidente. $\mathrm{O}$ PFZ não constituía um programa como os demais, uma vez que não se incluía entre os programas descritos no plano plurianual. Seus recursos financeiros também eram importantes: o orçamento federal previsto em 2003, R \$ 1,8 bilhão, era superior à maioria dos demais ministérios e não seria contingenciado (Suplicy 2003; Takagi 2006). Cabe lembrar que o programa de transferência de 
renda Cartão Alimentação abrangia 67\% dos recursos do programa (Takagi 2006).

O desamparo paulatino a que foi submetido o PFZ pode ser explicado por um confronto entre paradigmas de políticas públicas: a segurança alimentar defendida pelos funcionários ingressantes e os programas de transferências de renda defendidos por alguns setores da burocracia federal. Alguns dos cargos de confiança da administração Lula ligados ao MESA possuíam uma agenda própria: pôr em prática o PFZ. Alguns haviam participado da formulação da proposta no Instituto da Cidadania. No entanto, gestores de programas de transferência de renda e atores políticos defendia a importância de consolidar práticas já em curso, como o Cadastro Único (Monteiro 2011). Destacam-se pelo menos três grupos entre os que disputavam espaços e recursos de poder com o Fome Zero: (i) o ligado ao Bolsa Escola (Cristóvão Buarque), no Ministério da Educação (Coelho 2010); (ii) o grupo do Ministério da Assistência Social, que posteriormente ocuparia a Secretaria Nacional de Renda e Cidadania no MDS, responsável por gerenciar o programa Bolsa Família (Rosani Cunha), e (iii) o grupo responsável pela unificação dos programas de transferência de renda, entre 2003 e 2004, liderado pela pesquisadora Ana Fonseca, oriunda da experiência de Renda Mínima do município de São Paulo (Leite \& Peres 2015). Do ponto de vista das coalizões de causa ou de defersa, duas outras coalizões além da "segurança alimentar" se mobilizaram: "capital humano" e "renda incondicionada" (Tomazini 2010a, Tomazini 2010b).

O processo de aprendizagem institucional também é destacado por Francisco Menezes, em entrevista, para quem a mudança não ocorreu em termos de prioridade, mas como

"resultado de um amadurecimento sobre a política pública a ser aplicada. O Fome Zero tinha como principal instrumento o Cartão Alimentação, com obrigação de uso do recurso na compra de alimentos. Foi feita uma revisão nessa proposta e com o Bolsa Família deixou-se à livre escolha do beneficiado a finalidade de uso do recurso" (Fracisco Menezes 2009).

O Fome Zero estava baseado em um conjunto de ideias mais intervencionistas do ponto de vista econômico: investimentos para baratear o preço dos alimentos, intervenção na economia territorial para a dinamização da economia local, fortalecimento dos pequenos produtores, por meio da compra e venda de produtos, entre outros. Esse conjunto de ideias não se articulava bem com as ideias dominantes do paradigma do "capital humano" 18 , em que a pobreza é vista como um problema de ordem mais individual, de capacitação e de educação para a sobrevivência no mercado de trabalho. Os atores que defendiam a preeminência dos programas de transferências condicionadas insistiam que o governo federal havia desprezado os "avanços na estrutura de combate à pobreza ocorrida em anos anteriores, como a chamada Rede de Proteção Social, que continha entre outros programas o Bolsa-Alimentação e o Bolsa-Escola" (Neri 2005, p.44). Desse modo, o PFZ teria incorrido "no pecado original: o de reinventar a roda", pois o Bolsa Família "representa uma tentativa de retomar o uso de tecnologias sociais de ponta, de dar maior consistência e sistematicidade às ações do governo federal" (ibid.). A claridade cognitiva e a simplicidade das ideias dos programas de transferência de renda também se apoiavam largamente no seu caráter pouco participativo. Enquanto a coalizão favorável aos programas de transferências condicionadas apresentava-os como a "modernidade" em matéria de políticas sociais, as divisões internas no governo sobre como implementar o programa também contribuíram para a erosão do apelo ao Fome Zero.

O PFZ apresentava uma desvantagem em relação aos programas de transferência de renda condicionada por seus objetivos amplos e suas ações em 
19 Traduções de língua estrangeira são de responsabilidade das autoras.

${ }^{20}$ Cf. Economista acha estratégia do Fome Zero ultrapassada (2003). várias temporalidades (estruturais emergenciais e específicas). O programa também exigia um grande esforço de coordenação entre os diferentes ministérios, estados e municípios, além de envolver canais participativos como os conselhos, conferências nacionais, mesas de diálogo com movimentos sociais, empresários, organizações de classe. Com um desenho complexo, não havia uma clareza sobre suas formas de operacionalização. No seio do PFZ havia uma discordância quanto aos instrumentos, enquanto alguns atores insistiam na importância da mobilização e da participação popular dando autonomia às decisões dos comitês gestores, outros preferiam dar ênfase ao papel das prefeituras. Em entrevista, Frei Betto revela o caráter conflituoso quanto às crenças sobre o papel da sociedade e do Estado na implementação do programa: "ao descartar o Fome Zero e optar pelo Bolsa Família, o governo federal escolheu o pacto federativo em detrimento da mobilização da sociedade. Portanto, descartou os Comitês gestores e favoreceu os prefeitos, que nem sempre primam pelo bom uso dos recursos públicos". Francisco Menezes, a esse respeito, aponta que

"de fato, com o Bolsa Família ocorre essa inflexão, abandonando-se os antigos comitês gestores do Fome Zero e privilegiando-se a relação com os poderes públicos estaduais e municipais. Este foi um dos pontos mais polêmicos na implantação do programa, já que a perda de poder dos comitês gestores foi muito sentida por aqueles que estavam investidos dessa responsabilidade e os municípios não aceitavam submeter-se ao controle desses comitês gestores" (Francisco Menezes 2009).

Isso resultou em uma perda de confiança no paradigma da segurança alimentar como referência dominante das políticas de luta contra a pobreza. Comparativamente, os programas de transferência condicionada de renda não possuíam tamanha complexidade e se mostravam como um modelo mais simples e viável de política pública. Apresentado de forma complexa, os gestores do PFZ abriram espaço para os oponentes apontarem de maneira contundente a falta de clareza de suas propostas.

No que diz respeito aos aspectos normativos apontados por Campbell (1998), ainda que as ideias sejam viáveis e instrumentalmente eficazes, é necessário que as soluções sejam politicamente aceitáveis e legítimas junto ao público em geral. Como frames, as ideias parecem não ter contribuído de forma importante na crise do PFZ. O processo de framing, que "oferece aos atores símbolos e conceitos que servem de soluções aos problemas de políticas públicas em termos normativamente aceitáveis por meio da transposição e da bricolagem" (idem, p.394) ${ }^{19}$, ocorreu, sobretudo, com a estratégia de simplificar o conceito de segurança alimentar por meio do emprego do termo "fome". A questão da fome, além de dar sentido simbólico ao programa social, apontava para o malogro das propostas de luta contra a pobreza previamente apresentadas. Combinada com outros apelos (mobilização, solidariedade etc.), a fome aparece nos discursos e nos pronunciamentos de forma a angariar apoio político para o programa. Para além do recurso à fome em detrimento da campanha pela "segurança alimentar", fez-se também uso de imagens da seca e figuras históricas de prestígio, como Betinho, por exemplo. No entanto, a estratégia da utilização nos meios de comunicação do termo "fome" pode ter contribuído à incompreensão quanto aos objetivos do programa e ao apelo ao direito à alimentação. Muitos especialistas em políticas de luta contra a pobreza criticaram a orientação da segurança alimentar e da difusão da imagem de um "Brasil que tem fome"

Com relação ao segundo aspecto normativo apontado por Campbell (idem), pode-se perceber uma dicotomia entre as imagens propaladas pela grande mídia (negativas) e o sentimento público mensurado por surveys e enquetes de opinião pública (positivas). Em uma pesquisa realizada pelo Datafolha (2003), a fome e 
a miséria foram apontadas como o segundo principal problema do país por $15,1 \%$ dos entrevistados, ficando somente atrás do desemprego (31,7\%). Nessa pesquisa, os dois mandatos do Fernando Henrique com relação ao combate à fome e à miséria foram avaliados como péssimo $(31,3 \%)$, ruim $(22,2 \%)$ e regular $(29,1 \%)$. Do total de entrevistados, $46,6 \%$ avaliaram que o governo Lula seria bom nessa área, seguidos de 31,3\% bom e 15,2\% regular. O programa permaneceu bem avaliado no ano seguinte. Segundo pesquisa do Ibope realizada em setembro de 2004, a área de combate à fome e à pobreza foi apontada como a área de melhor desempenho do governo Lula $(25,2 \%)$. Um resultado consideravelmente acima das demais áreas avaliadas, como as ações para reduzir o desemprego (8,8\%), ações na área da saúde (7\%) e da educação $(6,2 \%)$. Apesar da pressão midiática contrária, as pesquisas de opinião apontam para um sentimento público favorável à permanência desse programa.

Como argumentamos, os atores críticos nesse processo de crise do Fome Zero, tanto dentro do Estado como da sociedade, não estavam simplesmente promovendo seus próprios interesses, mas estavam defendendo crenças e causas distintas. No entanto, o recurso ao poder não deixa de ser importante. A coalizão da segurança alimentar perdeu espaço político com a criação do Grupo Interministerial para a unificação dos programas de transferência de renda. Esse rearranjo representou a perda da autonomia do programa com mais recursos dentro do PFZ: o Cartão Alimentação. No curso do primeiro ano de governo, formuladores de políticas contrários aos princípios do PFZ, alocados principalmente na Casa Civil e no Ministério da Fazenda (Tomazini 2010a; 2010b; 2015) dispunham de uma posição de poder privilegiada. Além disso, a reforma ministerial no final de 2003 contribuiu para a perda de poder político da coalizão segurança alimentar, uma vez que o MESA foi extinto com a criação de uma grande pasta: o Ministério do Desenvolvimento Social, que alçou o Programa Bolsa Família como a grande vitrine na área social do governo Lula. Resultado de um processo de aprendizado político que implicou na alteração de comportamentos a partir das experiências concretas, a mudança que levou ao abandono do PFZ foi acarretada por fatores externos e notadamente por fatores internos relativos à interação entre os grupos de atores.

\section{Conclusões}

Buscamos discutir alguns pontos sobre: (i) o processo histórico de formação do paradigma de políticas públicas da segurança alimentar; (ii) a construção de uma advocacy coalition ligada à essa temática dentro e fora do PT; (iii) a implementação do PFZ e, por fim, (iv) as hipóteses sobre a crise do programa. No plano teórico, tratamos de entender melhor como os diferentes tipos de ideias afetaram a formulação do PFZ. Seguindo as premissas de Campbell (1998, p.400), o êxito e a crise do PFZ, como ideia programática, dependeu, em parte, da medida em que forneceu soluções inovadoras para problemas sociais seculares, acomodou-se em paradigmas sedimentados e legitimados de forma bottom-up, obteve apoio de setores estratégicos, beneficiou-se de um sentimento público e de um contexto favorável à implementação de programas de combate à fome e à pobreza.

No entanto, o macroprojeto político do PT, que chegou ao poder em 2003, sofreu um processo de aprendizagem política. As prerrogativas do programa Fome Zero (propostas pela coalizão de atores que defendem a causa da segurança alimentar, e que foram construídas desde os anos $1990 \mathrm{em}$ importantes think tanks ligados ao partido) não sobreviveram diante das dificuldades institucionais e políticas colocadas no exercício da governabilidade. Além disso, a disputa com outras coalizões de causa e a complexidade programática do programa demonstraram ter um papel importante para a deslegitimação dessa 
${ }^{21}$ Cabe notar que outras políticas relacionadas com o combate à fome e à insegurança alimentar foram expandidas como a Alimentação Escolar e para o Programa de Aquisição de Alimentos da Agricultura Familiar (PAA). proposta política. O presidente Lula agiu como empreendedor kingdoniano do projeto de combate à fome e à pobreza de forma perene, porém "metamorfoseando-se" em termos do paradigma já no primeiro ano de governo. O Bolsa Família passou a concretizar a partir de 2004 uma bandeira política mais capitalizável, viável e de identificação "orgânica” com as lutas históricas do partido, deslocando do centro do macroprojeto político do PT na área social o PFZ e o paradigma de segurança alimentar.

A difusão das novas ideias e novos princípios de ação pública não ocorre de forma a fazer "tábua rasa" das matrizes cognitivas e normativas anteriormente legítimas, mas se constitui como o ponto de referência com o qual devem se adaptar essas estruturas mais antigas. Assim, apesar de não se constituir mais como um eixo programático e político da área, o paradigma da segurança alimentar parece ter sofrido um processo de decodificação-recodificação (Surel 1998, p.168), permanecendo como um dos três segmentos do Ministério de Desenvolvimento Social ${ }^{21}$. Seu atual organograma demonstra que houve uma acomodação dos grupos políticos ligados a diferentes paradigmas dentro do mesmo locus institucional: convivem sob o mesmo guarda-chuva ministerial a Assistência Social, a Segurança Alimentar, o Bolsa Família e o Brasil Sem Miséria. Além disso, o Fome Zero permanece como uma referência de políticas públicas internacionalmente reconhecida.

Carla Guerra Tomazini (carlatomazini@gmail.com) é Doutora em Ciência Política pela Universidade Estadual de Campinas (Unicamp), em cotutela com a Université Sorbonne Nouvelle, Paris 3, Institut des Hautes Etudes de l'Amérique latine (França). Vínculo institucional: Centre de Recherche et de Documentation des Amériques (CREDA), Université Sorbonne Nouvelle-Paris 3, Paris, França.

Cristiane Kerches da Silva Leite (ckerches@ uol.com.br) é Doutora em Ciência Política pela Universidade de São Pauo (USP) e Professora do curso de graduação e pós graduação em Gestão de Políticas Públicas da EACH/USP. Vínculo Institucional: Curso de Graduação e Pós-graduação em Gestão de Políticas Públicas, USP, São Paulo, SP, Brasil.

\section{Referências}

Almeida, M.H.T.A., 2004. A política social no governo Lula. Novos Estudos, 70, pp.7-18. 2005. Recentralizando a federação? Revista Sociologia Política, 24, pp.29-40. DOI: 10.1590/S010444782005000100004

Barros, R.P.; Henriques R. \& Mendonça, R., 2001. A estabilidade inaceitável: desigualdade e pobreza no Brasil. Texto para discussão, 800. Rio de Janeiro: IPEA.

Baumgartner, F. \& Jones, B., 2009. Agendas and Instability in American Politics. Chicago: University of Chicago Press.

Belik, W., 2003. Perspectivas para segurança alimentar e nutricional no Brasil. Saúde e Sociedade, 12(1), pp.12-20. DOI: $10.1590 /$ S0104-12902003000100004

Bourne, R., 2008. Lula of Brazil: The Story So Far. London: Zed Books.

Campbell, J.L., 1998. Institutional Analysis and the Role of Ideas in Political Economy. Theory and Society, 27(3), pp.377-409. DOI: $10.1023 / \mathrm{A}: 1006871114987$

2002. Ideas, Politics and Public Policy. Annual Review of Sociology, 28, pp.21-38. DOI: 10.1146/annurev.soc.28.110601.141111

Campos, H.K.T. \& Abreu, M.F., 2010. Fome Zero e as parcerias: dos alimentos aos telecentros. In , eds. Fome Zero: uma história brasileira. Brasília: MDS.

Coelho, D.B. 2010. Competição política e a nova agenda social: por que os partidos políticos de esquerda e direita difundiram programas de transferência de renda no Brasil? In $13{ }^{\circ}$ Congresso BIEN (Basic Income Earth Network). São Paulo.

Cohen, M.; March J. \& Olsen, J., 1972. A Garbage Can Model of Organizational Choice. Administrative Science Quarterly, 17(1), pp.1-25. DOI: 10.2307/2392088

Datafolha, 2003. Avaliação do Presidente Luiz Inácio Lula da Silva. . DATAFOLHA/BRASIL03.JUN-01836. In Banco de Dados do Centro de Estudos de Opinião Pública. CESOP-UNICAMP. Disponível em: http://www.cesop.unicamp.br/busca/CESOP/pesquisa_usuario. Acesso em: 21 novembro 2013.

Faria, C.A.P., 2003. Idéias, conhecimento e políticas públicas: um inventário sucinto das principais vertentes analíticas recentes. Revista Brasileira de Ciências Sociais, 18(51), pp.21-30. DOI: 10.1590/S0102-69092003000100004

Gomes da Silva, J., 1993. Entrevista concedida a Renato Simões. Teoria e Debate, 21, maio-julho. 
Gordillo, G. \& Gómez H., 2005. Conversaciones sobre el hambre. Brasil y derecho a la alimentación. Cámara de Diputados. Legislatura LIX. Mexico: Centro de Estudios para el Desarrollo Rural Sustentable y la Soberanía Alimentaria.

Hall, A., 2006. From Fome Zero to Bolsa Família: Social policies and poverty alleviation under Lula. Journal of Latin American Studies, 38(4), pp.689-709. DOI: 10.1017/s0022216x0600157x

Hall, P., 1993. Policy Paradigms, Social Learning and the State: The Case of Economic Policymaking in Britain. Comparative Politics, 25(3), pp.275-296. DOI: 10.2307/422246

Haas, P., 1992. Introduction: Epistemic communities and international policy coordination. International Organization, 46 (1), pp.1-35.

Heclo, H., 1974. Modern Social Policy in Britain and Sweden. New Haven: Yale University Press.

Howlett, M.; Ramesh, M. \& Perl, A., 2013. Política Pública: seus ciclos e subsistemas (uma abordagem integradora). $3^{\mathrm{a}}$ ed. Rio de Janeiro: Elsevier.

Hunter, W. \&AMP; POWER, T., 2005. Lula's Brazil at Midterm. Journal of Democracy, 16(3), pp.127-139. DOI: .1353/jod.2005.0046

Jobert, B. \& Muller, P., 1987. L'Etat en action. Politiques publiques et corporatismes. Paris: Presses Universitaires de France.

Kingdon, J., 2003. Agendas, Alternatives, and Public Policies. New York: Harper Collins.

Leite, C.K.S. \& Peres, U.D., 2015. Paradigmas de Desenvolvimento e Disseminação de Políticas: Raízes Locais da Criação do Programa Bolsa Família. Organizações \& Sociedade, Salvador, v. 22, n. 75, p. 621-638. DOI: 10.1590/1984-9230758

Martins, G.A. \& Theóphilo, C.R., 2009 Metodologia da investigação cientifica para Ciências Sociais Aplicadas. São Paulo: Atlas.

Monteiro, C.A., 2003. Aumentar o valor do programa bolsa escola é mais consistente. PUC Viva, 5(19), pp.26-28.

Monteiro, I.R., 2011. Integração de políticas sociais: um estudo de caso sobre o Bolsa Família. Rio de Janeiro. Dissertação (Mestrado Profissional em Bens Culturais e Projetos Sociais). Fundação Getúlio Vargas.

Moura, P.G.M., 2007. Bolsa família: projeto social ou marketing político? Katálysis, 10(1), pp.115-122.

Neri, M.C., 2005. Dois anos de política social. Conjuntura Econômica, 1, pp.44-45.

Orloff, A.S. \& Skocpol, T., 1984. Why not Equal Protection? Explaining the politics of public social spending in Britain, 1900-1911, and the United States, 1880s-1920. American Sociological Review, 49(6), pp.726-750. DOI: $10.2307 / 2095527$

Pierson, P., 2000. Increasing Returns, Path Dependence, and the Study of Politics.American Political Science Review, 94(2), pp.251-267. DOI: $10.2307 / 2586011$. 2004. Politics in Time.History, Institutions, and Social Analysis. Princeton: Princeton University.

Radaelli, C., 2013. The Politics of Corporate Taxation in the European Union: Knowledge and international policy agendas. London: Routledge.

Sabatier, P. \& Jenkins-Smith, H., 1993. Policy Change and Learning: An advocacy coalition approach. Boulder: Westview. 1999. Theories of the Policy Process. Boulder: Westview.

Schmidt, V., 2010. Taking Ideas and Discourse Seriously: Explaining change through discursive institutionalism as the fourth 'new institutionalism'. European Political Science Review,2(1), pp.1-25. DOI: 10.1111/j.1467-9248.2012.00967.x

Silva, J. G.; Belik W. \& Takagi, M., 2002. Para os críticos do Fome Zero. Teoria e Debate, 51, 1 jun. 2002. Disponível em: http://www.teoriaedebate.org.br/materias/nacional/para-os-criticos-do-fome-zero. Acesso em: 23 abr. 2016.

,2006. Os desafios de uma política de Segurança Alimentar no Brasil. In A. Cimadamore; D. Hartley \& J. Siquiera, eds. A pobreza do Estado: reconsiderando o papel do Estado na luta contra a pobreza global. Buenos Aires: CLACSO.

Skocpol, T., 1979. States and Social Revolutions. Cambridge, UK: Cambridge University Press.

1985. Bringing the State Back In: Strategies of analysis in current research. In P.E. Evans; D. Rueschemeyer \& T.Skocpol, eds. Bringing the State Back In. New York: Cambridge University Press.

Suplicy, E.M., 2003. Programa Fome Zero do Presidente Lula e as perspectivas da Renda Básica de Cidadania no Brasil. Saúde e Sociedade, 12(1), pp.61-71. DOI: 10.1590/S0104-12902003000100009

Surel, Y., 1998. Idées, intérêts, institutions dans l'analyse des politiques publiques, Pouvoirs, 87, pp.161-178. DOI: $10.4000 /$ articulo.60

Takagi, M., 2006. A implantação da política de segurança alimentar e nutricional no Brasil: seus limites e desafios. Campinas. Tese (Doutorado em Economia). Unicamp.

Tomazini, C., 2010a. La construction des politiques de transferts monétaires conditionnels: entre consensus et dissentiments. Une analyse de la lutte contre la pauvreté au Brésil et au Mexique. Paris. Dissertação de Mestrado. Institut des Hautes Études de l'Amérique Latine, Université Paris III. ,2010b. As coalizões de causa em torno das políticas de transferências condicionada: olhar cruzado Brasil-México. Carta Internacional, 5, pp.37-55.

, 2015. A disputa pela gestão e participação nas políticas de luta contra a pobreza nos primeiros anos Lula: o caso dos comitês gestores do cartão alimentação, In: E. Carlos; O.P. Oliveira \& W.M. Romao, eds. Sociedade civil e políticas públicas: atores e instituições no Brasil contemporâneo. Chapecó: Argos Editora Universitária.

Weir, M. \&AMP; SKOCPOL, T., 1985. State Structures and the Possibilities for `Keynesian’ Responses to the Great Depression in Sweden, Britain, and the United States. In P.E. Evans; D. Rueschemeyer \& T.Skocpol, eds. Bringing the State Back In. New York: Cambridge University Press.

Yazbek, M.C., 2003. Fome Zero: uma política social em questão. Saúde e Sociedade,12(1), pp.43-50. 
M. C. 2004. O programa fome zero no contexto das políticas sociais brasileiras. São Paulo em Perspectiva, vol.12 (2), pp.104-112.

\title{
Artigos em jornais
}

Brazil's War on Hunger off to a Slow Start, 2003. International New York Times, 30 mar. Disponível em: http://www.nytimes.com/2003/03/30/world/brazil-s-war-on-hunger-off-to-a-slow-start.html. Acesso em: 27 fev. 2015.

Cheque de Gisele Bündchen para o Fome Zero foi depositado hoje. 2003. Folha de S. Paulo, 18. mar. Disponível em: http://www1.folha.uol.com.br/folha/brasil/ult96u47149.shtml. Acesso em: 27 fev. 2015.

Economista acha estratégia do Fome Zero ultrapassada. 2003. Folha de S. Paulo, 30.jan. Disponível em: http://www1.folha.uol.com.br/fsp/brasil/fc3001200308.htm Acesso em: 27 fev. 2015.

Fome Zero: muito samba, pouco enredo, 2001. Estado de S. Paulo, 21 oct. Disponível em: http://acervo.estadao.com.br/pagina/\#!/20011021-39450-spo-8-pol-a8-not/busca/Instituto+Cidadania. Acesso em: 27 fev. 2015.

Ibope, 2004. Pesquisa com eleitores. IBOPE/BRASIL04.SET-02070. In: Banco de Dados do Centro de Estudos de Opinião Pública. CESOP-UNICAMP. Disponível em: http://www.cesop.unicamp.br/busca/CESOP/pesquisa_usuario. Acesso em: 21 nov. 2013.

Instituto Cidadania, 2001. Projeto Fome Zero: uma proposta de política de segurança alimentar e nutricional para o Brasil. Disponível em: www.fomezero.gov.br/download/ livro_projeto\%20fome.pdf. Acesso em: 18 maio 2014.

Programa Fome Zero tem início em meio a críticas e indefinições quanto a sua estrutura, 2003. Época Online, 30 jan. Disponível em: http://revistaepoca.globo.com/Epoca/0,6993,EPT478322-1659,00.html. Acesso em: 27 fev. 2015.

Oposição ataca o Fome Zero; Graziano admite dificuldades. 2003. Folha de S. Paulo, 27.mar. Disponível em:http://www1.folha.uol.com.br/fsp/brasil/fc2703200315.html. Acesso em: 27fev. 2015.

\begin{abstract}
The paper examines the design process and the progressive abandonment of the Hunger Zero Program (Fome Zero - HZP) as main strategic line for the actions of the federal government between 2003 and 2004. The objective is to analyze the ideas that underpinned the structure of political food security and hypotheses on crisis program and strategic redirection for the unification of the cash transfer programs that led to the creation of the Bolsa Família. The research methodology consists of the analysis of primary qualitative data (semi-structured interviews with policy program) and secondary data (newspaper reports and publications produced by expert researchers in the subject and analytical work on HZP). The theoretical framework used is the cognitive and post-positivist policy analysis. After examining the development of food security paradigm at both the international and domestic levels, the present study focuses on analyzing four explanatory hypotheses concerning the HZP crisis: previous institutional arrangements, conflict between paradigms, loss of influence in the "food security" coalition and programmatic complexity of the program. It is argued that the program is an important element to understand not only the political game and managerial problems faced by the newly established government at the time, but the contest of ideas and paradigms (Campbell 1998, Hall 1993) in which actors and coalitions (Sabatier and Jenkins-Smith 1993) seek to influence of anti-hunger and poverty policies in during Lula's first term.
\end{abstract}

KEYWORDS: poverty; food security; cash transfer programs; paradigms; advocacy coalition framework.

This is an Open Access article distributed under the terms of the Creative Commons Attribution Non-Commercial License which permits unrestricted non-commercial use, distribution, and reproduction in any medium provided the original work is properly cited. 